\title{
Eu e ser [Sein]. A imagem de Deus e o mundo construído
}

\section{Christoph Asmuth}

\section{Q OpenEdition}

Journals

Edição electrónica

URL: http://journals.openedition.org/ref/1142

DOI: $10.4000 /$ ref. 1142

ISSN: 2258-014X

Editora

EuroPhilosophie Editions

Refêrencia eletrónica

Christoph Asmuth, «Eu e ser [Sein]. A imagem de Deus e o mundo construído », Revista de Estud(i)os sobre Fichte [Online], 19 | 2019, posto online no dia 01 dezembro 2019, consultado o 08 setembro 2020. URL : http://journals.openedition.org/ref/1142 ; DOI : https://doi.org/10.4000/ref.1142

Este documento foi criado de forma automática no dia 8 setembro 2020

(C) EuroPhilosophie 


\title{
Eu e ser [Sein]. A imagem de Deus e o mundo construído
}

\author{
Christoph Asmuth
}

A filosofia de Fichte segue um caminho anteriormente aberto por Kant. Esse caminho significa o fim da metafísica clássica e o início de um novo e metódico princípio na filosofia. Uma pergunta importante que a nova filosofia transcendental deveria responder diz respeito ao ser; melhor: o status do ser. A tradição aponta para a origem do ser e a filosofia era em seu âmago o pensamento do ser enquanto ser. A identidade preponderante da identidade do ser e de Deus então foi dissolvida através da identidade de Deus e eu. O ser obtém com isso apenas um papel secundário. Isso corresponde ao caminho pensante do conceito de substância ao de função ${ }^{1}$.

A dissolução do papel primordial do ser já marca o posicionamento autônomo de sua filosofia. Na Doutrina da Ciência 1794/95, Fichte se decide por uma nova proposição da filosofia dos princípios [Prinzipienphilosophie]. Com isso, ele segue um design teórico assumido de Spinoza, que já determinava o desenvolvimento da filosofia transcendental em Carl Leonhard Reinhold: filosofia proveniente de um fundamento [Grundsatz]. Filosofia deveria ser fundamental [grundsätzlich]. O programa de uma filosofia fundamental [grundsätzlichen] tenta sistematizar a heterogeneidade das três críticas de Kant e conectá-la à pretensão de certeza [Gewissheitsanspruch] da Ethica de Spinoza. Fichte percebe muito bem a situação de confusão da filosofia no final do século XVIII. Ele reconhece que principalmente Salomon Maimon se encontra na posição de recusar as objeções vulgares e céticas contra a filosofia de Kant e Reinhold, entre elas, explicitamente, a resenha de Garve-Feder e a crítica de Friedrich Heinrich Jacobis. Salomon Maimon desenvolve a proposição da possibilidade de determinação [Bestimmtbarkeit] enquanto fundamento da filosofia. Com isso ele abre a porta para uma interpretação ideal-realista da filosofia de Kant, que desvia tanto do enfadonho debate em torno da Coisa em si quanto da acusação de um idealismo subjetivo. A posição de Maimon permanece um motivo leibniziano lógico e engessado na história do desenvolvimento da clássica filosofia alemã². 
Fichte nunca demonstrou muita sensibilidade para a lógica. Em Jena, Erlangen e Berlim suas observações sobre a lógica deixam a desejar. Ao Fichte faltam os conhecimentos necessários para formar uma questão lógica fundamental que se refira à relação da prima philosophia à lógica e delinear uma nova lógica, como anteriormente tentou Maimon e posteriormente Hegel realizou ${ }^{3}$. Ao conhecimento insuficiente se adiciona um desinteresse. É um erro fundamental propor unicamente o racionalismo à filosofia de Fichte e analisar sua filosofia exclusivamente como uma consequência das deduções dialéticas. Ele não é um idealista racional. Em sua biografia, sensibilidade, tempestuosidade e ímpeto e piedade são intimamente costurados com sua leitura de Kant. Sua filosofia se endereça ao homem como um todo. Sua filosofia deságua na vida. o homem como um todo não é dividido em corpo e alma. Sentimentos não são separados da razão. Por isso, a ética não é uma teoria do conhecimento, a religião não é separada da política e a natureza da cultura. Fichte consegue distinguir esses domínios, pois ele pode formar e gerar essas diferenças. Fazer uma diferença significa a produzir e não que esta seja anteriormente dada. A lógica aparece como uma disciplina que é completamente isolada da vida. Ela é um ponto milagroso [wunder] na filosofia de Fichte que se direciona ao todo [Ganzheit]. Por isso ele a tenta incluir no todo da vida e do ser. Todavia, ele só alcança isso em partes.

Pode-se designar isso como uma experiência fundamental da modernidade. Racionalismo e empirismo se distinguem mais ou menos do mesmo modo através de estratégias isoladas. $\mathrm{O}$ ser humano se aliena da natureza, o único da sociedade. A luta de Fichte contra o feudalismo e para uma sociedade homogênea partindo do 'povo' é uma reação às forças intrínsecas de fuga e separação da principiante modernidade. Por isso que Napolão deve ter o impactado como uma figura assustadora. No seu impulso jacobino, primeiramente, Fichte admira o revolucionário corso, assim como em seguida repudia o usurpador ditatorial.

A leitura da teoria do juízo de Kant transporta a filosofia transcendental a outra esfera. Ele amplia o projeto, no que ele escolhe outro termo fundamental. Em contraposição ao conceito de Kant sobre o juízo, Fichte aponta para o conceito do conhecimento [Wissen] ou da consciência ${ }^{4}$. Fichte decide por um amplo conceito de conhecimento [Wissensbegriff], que não contém apenas momentos cognitivos ou discursivos, mas também emotivos e sensíveis. Através da mudança da teoria do juízo para a teoria do conhecimento ele não apenas amplia a área de alcance da filosofia transcendental, ele radicaliza seu programa e sua pretensão [Anspruch]. Enquanto Kant ainda pressupõe duas fontes, dois elementos fundamentais para o reconhecimento e formação dos juízos, a saber, sensibilidade e razão, Fichte ignora essa dicotomia e troca-a por uma fonte ${ }^{5}$. Uma teoria da imanência, que não é bem solipsismo ou idealismo subjetivo. Com isso Fichte quer alcançar um alto nível de unidade e homogeneidade no princípio do conhecimento, uma determinação estrutural universal de todas as formas conscientes e a autonomia absoluta do sujeito tratado como maior exigência da moral [Sittlichkeit] ${ }^{6}$. No entanto, por outro lado, para Fichte, a diversidade e a heteronomia precisam se tornar uma decisiva questão chave. Para ele isso não se trata da facticidade do fato, a diversidade fática, que sempre se encontra para Fichte além da dedutibilidade. Muito mais, a indisponibilidade do real [Unverfügbarkeit des Wirklichen] na perspectiva teórica e a disponibilidade do real [Verfügbarkeit des Wirklichen] na perspectiva do prático necessitam de uma justificativa especial. 
Nessa posição filosófica, Fichte desenvolve sua teoria da imagem [Bildes] e da formação [Bildung], uma estreita aproximação do religioso, do educativo e do especulativo, relações sempre dinâmicas. Com isso, imagem é um conceito que designa uma diferença imanente. Na imagem se esconde um núcleo dinâmico: o formar [Bilden, Formen], criar, produzir. Formar [bilden] é um processo genético, controlado, direcionado e ativo. De acordo com a etimologia, imagem [Bild] não é apenas um conceito dinâmico, um verbo substantivado, mas também possui o duplo significado de modelo [Vorbild] e imagem [Abbild].

Fichte concebe sua ampliada teoria da consciência como uma teoria da imagem [Bildtheorie]. Com isso, no decorrer do desenvolvimento de sua doutrina da ciência, o conceito de imagem [Bildbegriff] substitui o conceito de conhecimento em diferentes conjunturas, porém, sem substituí-lo completamente. Nisso, Fichte utiliza o duplo sentido inerente ao conceito de imagem: simultaneamente moldador [formend] e moldado [geformt], formador [bildend] e ser formado [gebildet $z u$ sein]. Atividade e passividade, produzir e ser produzido se encontram com isso na mesma medida no centro de sua reflexão. Fichte populariza ${ }^{7}$, ou melhor: seculariza a filosofia teológica, por exemplo, como ela é acentuada dentro de um quadro teórico neoplatônico ${ }^{8}$. Não se trata mais da relação do homem ao seu Deus transcendental e a um mundo terreno [diesseitigen], que é identificada e demonstrada de modo argumentativo através do conceito de imagem. Fichte tenta muito mais um atravessamento do problema da realidade mesma, que é concebido por ele como essencialmente prático, a saber, como uma organização moral do mundo.

Essa ideia se apoia no desenvolvimento a uma representação de reconhecimento e moralidade ligada ao papel do sujeito. Fichte pretende expor a relação de autonomia e representação como relação consigo mesmo [Selbstverhältnis]. Ele pensa em um conceito [Konzept] de unidade, que não existe em uma superfície meta [Metaebene ${ }^{9}$ ], mas sim em uma superfície da coisa [Sachebene] integral. Unidade não deve ser adquirida no caminho da abstração, mas deve ser justificada na Coisa em si. Para isso, faz-se necessário um forçamento conceitual, exatamente nos momentos da relação [Relation] que apresentam um aspecto de unidade. A unidade se torna com isso ela mesma uma categoria de relação [Relationskategorie]. Então, a tradição do conceito de imagem se oferece para se pensar essa diferença em unidade e a unidade na diferença ${ }^{10}$.

A doutrina do conhecimento não é uma teoria do surgimento real [realen] de nosso mundo real [wirklichen]. Ela segue a posição metodológica fundamental da filosofia transcendental e delineia uma filosofia que pesquisa as condições de possibilidade [Möglichkeitsbedingungen] do reconhecimento e da ação. Em Jena, a doutrina do conhecimento apresenta ainda duas partes, uma teórica e uma prática. A tarefa da parte teórica se trata da dedução da representação, de acordo com a terminologia da época, isso significa a derivação dos elementos estruturais da consciência empírica. Dentre eles encontram-se principalmente as categorias assim como as formas de percepção [Anschauungsformen] de lugar e tempo. Através de uma forma especial de dialética, a partir do eu inicial [anfänglichen Ich] da doutrina do conhecimento, Fichte gera um processo genético, no que as categorias são derivadas uma atrás da outra e separadas uma das outras. $\mathrm{Na}$ interação das categorias com as formas de percepção, como em Kant assim também em Fichte, forma-se a estrutura da consciência do objeto [Gegenstandsbewusstseins]. No final da parte teórica, precisa-se chegar à consciência real [wirklichen Bewusstsein], uma transição, que também se pode identificar como a 
transformação das puras condições de possibilidade [Möglichkeitsbedingungen] em condições de realidade [Wirklichkeitsbedingungen]. Concordando com Kant, Fichte reconhece na força de formação [Einbildungskraft] uma riqueza que transmite percepção [Anschauung] e conceito puro [reinen Begriff], o que possibilita a representação; porém, de modo mais ferrenho que Kant, Fichte força para sua função produtiva, isto é, sua função criadora.

A força de formação é uma riqueza formadora de imagem, que, no processo de formação de imagem, nega-se a si própria, com isso tornando possível que a imagem criada se mostre a nós [uns entgegentritt] como mundo externo real. Enquanto em Kant a representação [Vorstellung] ainda se encontra em primeiro plano como representação [Repräsentation], ela se transforma em Fichte em presentação [Präsentation]. Enquanto Kant ainda marca uma Coisa-em-si como ponto de fuga da representação [Vorstellung], mesmo que seja meramente por razões metodológicas, isso é completamente cortado em Fichte. A mudança da representação representada [repräsentierenden Vorstellung] para a presentada [präsentierenden] é importante. Na presentação não existe mais aquele ponto de fuga, aquela âncora em um mundo externo concebido como sempre como real ${ }^{11}$.

Com isso, a filosofia de Fichte é subordinada à primazia do prático, da vida, do homem todo. Uma mera reconstrução dos elementos estruturais da representação [Vorstellung] no retorno [Rückgang] a suas condições de possibilidade não seria para Fichte unicamente insuficiente, mas também não cumpriria a tarefa da filosofia. Pois, de acordo com Fichte, filosofia não deveria principalmente ser: - um intelectualismo abstrato ou um racionalismo intelectualizado. Então, na verdade, a doutrina do conhecimento leva a estrutura de ação a se derivar como tal, no que ela mostra que o vazio [Leere] desse eu inicial [anfänglichen] e original [ursprünglichen] através do dado não-eu conquista seu conteúdo apenas com o retorno a si [Die Wissenschaftslehre leitet nun zwar die Handlungsstruktur als solche ab, indem sie zeigt, dass die Leere jenes anfänglichen und ursprünglichen Ich mit seinem durch es gesetzten Nicht-Ich erst in der Rückkehr zu sich selbst seine Inhalte gewinnt]; no entanto, esse retorno não é meramente uma fática autoreferência [Selbstbezüglichkeit], mas é caracterizada por Fichte como dever [Sollen], como um imperativo a se tornar o que se é originalmente, uma exigência ao eu de estar de acordo consigo mesmo, em uma palavra: o imperativo categórico ou a lei da moralidade [Sittengesetz] ${ }^{12}$. No direito da moral e da natureza [Sitten- und Naturrecht] essa lei da moral precisa de um ancoramento no mundo. Ela precisa de uma incorporação ${ }^{13}$. Segundo Fichte, isso é o corpo [Leib], que, desse modo, é uma função da lei da moral. A corporeidade [Leiblichkeit] do homem não é, de acordo com Fichte, uma condição inganhável [unhintergehbare], mas sim a expressão da atuação e do deveratuar, em última instância, uma expressão da tensão do eu e não-eu e a exigência que todo não-eu deva se tornar $\mathrm{eu}^{14}$.

Em Fichte, esse princípio corresponde a um conceito [Konzept] de corpo [Leibes], o qual não concebe a corporeidade [Körperlichkeit] do homem como estática. E é exatamente esse aspecto que se relaciona com o conceito de imagem de Fichte. Um famoso trecho da doutrina da moral [Sittenlehre] diz o seguinte:

Não existiria nenhuma determinação [Bestimmtheit] da articulação, mas [existiria] somente uma possibilidade de determinação [Bestimmtbarkeit] ao infinito; nenhuma formação do mesmo [do corpo; Ch. A.], mas apenas uma possibilidade de formar uma imagem [Bildsamkeit]. - breve, todos os animais são completos, e prontos, o homem é apenas aludido e delineado. 
Mais claro do que na filosofia teórica aparece aqui o aspecto formador do conceito de imagem em Fichte. Imagem [Bild], formação [Bildung] e possibilidade de formação [Bildsamkeit] abrangem um campo de palavras que, no todo, corresponde à relação mundana do homem. Ao mesmo tempo, com isso, Fichte se mostra como filho de seu tempo. O conceito da possibilidade de formação [Bildsamkeit] tem um papel muito importante no esclarecimento tardio. Com razão se pode indicar que a fonte de inspiração desse conceito se encontra em Jean Jacques Rousseau e, com isso, pode-se suspeitar que Fichte traduz o conceito da "perfectibilidade" para o alemão $0^{15}$. Pelo menos, encontra-se [liegt zu Grunde] uma ideia semelhante, a saber, a de que o homem, diferentemente do animal instintivo, é indeterminado no que se refere à natureza e, por isso, encontra-se aberto a diversos objetivos [Zwecksetzungen]. Em Fichte há a novidade de que esse conceito é sistematicamente inserido no campo conceitual da imagem [Bildes]. Nesse ponto, a possibilidade de formação [Bildsamkeit] não é apenas uma expressão para a possibilidade de mudança [Veränderbarkeit] do homem, mas, ao mesmo tempo, carregada das implicações práticas de uma autônoma autodeterminação do homem [Selbstbestimmung des Menschen] concebidas em cima de uma melhoria própria e do mundo. Assim como a força de formação cria uma imagem do mundo externo sem mundo externo, o homem deve ser uma imagem do eu absoluto, imagem ativa e produtora [aktives, hervorbringendes Bild], imagem formadora [bildendes Bild]. ${ }^{16} \mathrm{~A}$ condição para isso é a possibilidade de formação [Bildsamkeit], que não se refere à possibilidade arbitrária de deformação [Verformung], mas sim a imagem do absoluto formada na livre determinação de si.

Fichte e muitos outros pensadores de sua geração tinham muitas expectativas na formação [Bildung]. Eles buscavam uma imagem de homem emancipatória, que se alimentava da filosofia de Kant. Em sua filosofia prática, esse jogou uma carta que feriu [stach]. Essa era primeiramente o pensamento da autonomia, da autojulgamento[Selbstgesetzgebung]. Nenhuma instância superior, como um mando divino vindo de cima, como do Monte Sinai, deveria organizar as coisas humanas e exigir moral. O filósofo de Königsberg sabia muito bem que os tempos da teocracia haviam passado. No entanto, quando a superestrutura metafísica não podia mais assegurar a validade do mundo moral, no que ainda se poderia se segurar? Para Kant, na humanidade [Menschheit] presente em si e em cada pessoa. Ela é o que forma o núcleo do imperativo categórico. Humanidade [Menschheit] não como humanismo [Menschlichkeit], mas sim compromisso consigo próprio [Selbstverpflichtung] e núcleo autorreferente [selbstbezüglicher] de uma razão [Vernünftigkeit] autônoma que deveriam formar contra toda heteronomia o princípio de compromisso [Verpflichtungsgrund] de todas as ações morais. Quando Você age, esteja de acordo consigo, com a humanidade em Você, não se contradiga. No que Você representa para Você Seu próprio princípio [Maxime] como uma lei geral, Você pode verificar, se, em concordância Consigo, Você determina Sua vontade [Willen].

Paralelamente, Kant ligou essa teoria com a perspectiva que o homem não consegue formar nenhuma certeza [Gewissheit] sobre a própria moralidade de sua ação através da auto-pesquisa da consciência moral [Gewissens]. De acordo com Kant, isso impossibilita qualquer forma de soberba [Überheblichkeit] moral. Todo homem é perspectivamente limitado em seu conhecimento sobre sua própria moralidade ou também sobre a dos outros e, portanto, é por isso incapaz de se julgar moralmente e os outros. A isso Kant adicionou que o imperativo categórico poderia ser expresso de tal modo que ninguém 
poderia ser observado unicamente como meio, mas sempre também como fim. Ser fim em si mesmo é apenas outra manifestação da autonomia. Exatamente esse último aspecto é de grande importância para o conceito de formação [Bildungsbegriff].

Fichte, que assume a justificativa de Kant da moral sem metafísica, tirou disso que a formação [Bildung] não teria que reconhecer apenas o auto direcionamento ao fim [Selbstzweckhaftigkeit] do homem, mas ele refletiu que à possibilidade de ser imagem [Bildsamkeit] [característica] do homem deveria ser dada uma atenção especial. Sem uma justificativa para a possibilidade de se ser formado [gebildet], não é possível se pensar a formação [Bildung] de modo coerente [stimmig]. No fundo, encontra-se em Fichte um grande conflito entre um determinismo cosmológico e moral. De modo semelhante à visão científica [populärwissenschaftlichen Ansicht] amplamente difundida nos dias de hoje, segundo à qual não é o homem que pensa, age e aprende, mas sim seu cérebro, inicialmente pensava Fichte o cosmo como consequente de processos determinados de modo causal, o que eliminava tanto a liberdade de ação do homem como a possibilidade de ser imagem [Bildsamkeit]. Fichte confessa que foi a filosofia crítica de Kant que o libertou de uma opressão [Albdruck] de um completo determinismo causal. Então, ele se entusiasma [war er Feuer und Flamme] pela ideia da liberdade. A Carl Leonhard Reinhold, seu antecessor no cargo de professor em Jena, ele escreveu as famosas palavras: "Meu sistema é do início ao fim apenas uma análise sobre o conceito da liberdade." ${ }^{17}$. No entanto, possibilidade de ser imagem [Bildsamkeit] também dá prosseguimento ao trabalho de Fichte sobre o conceito de imagem. A opinião de Fichte sobre a imagem que se forma espontaneamente [vom sich selbst bildenden Bild] se encontra em segundo plano. A imagem não é um objeto passivo, não é uma coisa, mas é um processo ativo. De modo especificamente moderno, Fichte corrige com isso a forma bíblica de expressão que Deus teria criado o homem de acordo com sua imagem ${ }^{18}$ : Não é Deus que cria o homem como imagem, mas o homem que se cria como imagem, e não como cópia passiva de um ser anterior eterno [eines vorgängigen ewigen Seins], mas como imagem formadora [bildendes Bild], criando apenas aquilo que ele se capta como imagem [als dessen Bild es sich begreift]. A posição de Hegel nas Conferências sobre a filosofia da religião assim como a de Feuerbach na Essência do Cristianismo não são fundamentalmente diferentes da ideia de Fichte. De acordo com Fichte, o homem é livre por causa e na relação com Deus, que, segundo a decidida opinião de Fichte, não é nada mais que a causa da organização moral do mundo, a saber, a lei moral, ou seja, o Imperativo categórico.

No início essa liberdade é bem abstrata. Na base de toda Doutrina da Ciência 1793/94, a liberdade é a autonomia vazia de um eu que se estabelece sozinho. Esse eu não é nem uma coisa nem uma pessoa. É um constructo transcendental filosófico que serve unicamente para justificar a autorização da utilização de conceitos normativos e categoriais. O eu e com ele a doutrina da ciência pressupõem ação e conhecimento verdadeiros [wirkliches Handeln und Wissen] e pergunta pelo motivo da certeza dessa ação e conhecimento. Para isso Fichte desenvolve uma dedução reconstrutiva do operativo eu eterno [des handelnden endlichen Ich]. Dentre as condições que de modo geral possibilitam a liberdade operativa [handelnde Freiheit] se encontram individualidade, naturalidade [Natürlichkeit] e corporeidade [Leiblichkeit]. Diferentemente da maioria dos filósofos hoje em dia, Fichte pensa que não aparecemos na natureza com essas características, mas que são condições para a possibilidade para verdadeira liberdade. Individualidade, naturalidade [Natürlichkeit] e corporeidade [Leiblichkeit] não são justificadas em [uma] dimensão e função ontológica, mas sim em 
sua dimensão e função prática. Diferentemente do que se assume muitas vezes, Fichte dá à corporeidade um grande significado prático. A lei da moral não é apenas um imperativo formal; o eu finito não apresenta de modo aleatório um corpo [Leib] e é um ser vivo organizado com membros. Segundo Fichte, trata-se de uma relação argumentativa necessária: para que liberdade tenha realidade, o homem precisa na realidade conseguir produzir efeito na matéria, o que para ocorrer exige um corpo orgânico articulado ${ }^{19}$. Para Fichte, o auge da argumentação [argumentative Clou] consiste no que cada eu é, ao mesmo tempo, eu absoluto, sendo a tarefa prática como eu empírico, o eu absoluto se realiza em si [Der argumentative Clou besteht für Fichte darin, dass eines jeden Ich zugleich absolutes Ich ist, die praktische Aufgabe damit darin, als empirisches Ich, das absolute Ich in sich zu verwirklichen]. Nesse sentido, o eu é nós, a tradução de Fichte para a palavra da revolução: liberdade, igualdade, irmandade no filosófico.

Por isso, a possibilidade de ser imagem [Bildsamkeit] [característica] do homem não é uma situação cognitiva. A possibilidade de ser imagem [Bildsamkeit] também é corpórea [leiblich]. A doutrina educativa de Pestalozzis, que ele conheceu pessoalmente e passou a apreciar no seu tempo de tutor na família Ott em Zurique, direcionava-se ao homem como um todo. Assim também pensava Fichte. Ele não concebia uma doutrina educativa intelectualizada ou sequer racionalista, mas sim uma filosofia educativa [Bildungsphilosophie], que se direciona ao homem como um todo. Nisso ele utilizava a ponta anti-dual de sua filosofia, que não concebia o eu como contrário do corpo [Leib], mas sim [o concebia de modo] monadológico [monadologisch]. Uma alma imortal não conhece sua filosofia. Todavia [é] uma tarefa infinita. Ela consiste na progressiva realização da razão [Vernunft] no mundo. Fichte (1794) disse nas iniciais Conferências sobre a determinação dos estudiosos [Vorlesungen über die Bestimmung des Gelehrten]:

o último propósito de cada homem assim como de toda a sociedade, dentre os quais também todo o trabalho dos estudiosos na sociedade é o refinamento moral do homem como um todo. É o dever do estudioso sempre colocar esse último propósito e sempre o ter em vista em tudo que faz na sociedade.

A possibilidade de ser imagem [Bildsamkeit] não é sem propósito. Em Fichte, ela é apoiada de acordo com sua estrutura no aprimoramento social. Esses propósitos não são individualistas, mas consistem no desenvolvimento da sociedade, no desenvolvimento contínuo do eu finito ao absoluto.

Eu e ser são transmitidos pela imagem formadora [bildende Bild], uma transmissão [Vermittlung] que [se prova] como autotransmissão [Selbstvermittlung], uma autotransmissão [Selbstvermittlung] que se prova como autodeterminação. 0 ser perde sua função primordial, no que o eu é ao mesmo tempo molde e cópia do ser vivo. Se Deus tivesse criado o homem de acordo com sua imagem, então, o homem criaria seu mundo e si próprio de acordo consigo e a partir de si [nach und aus sich selbst]. $O$ ser se torna mera expressão de suas forças que operam de modo dinâmico. $O$ ser perdeu sua remota autenticidade; então, no seu lugar passa a reger o eu finito, que em seu absolutismo[Absolutheit], ou seja, a incondicionalidade do mandamento moral descobre e em processos de transformação infinitos transforma na vida [an seiner Stelle regiert nun das endliche Ich, das in sich seine Absolutheit, d.h. die Unbedingtheit des moralischen Gebotes entdeckt, und in unendlichen Bildungsprozessen in das Leben umsetzt]. Ao invés da autenticidade do ser, Fichte reconhece apenas a transmissão do eu finito consigo mesmo - um processo de formação real com o objetivo do homem se reconciliar com o mundo por ele formado [entworfenen]. 


\section{NOTAS}

1. Ver: CASSIRER, E. Substanzbegriff und Funktionsbegriff. Untersuchungen über die Grundfragen der Erkenntniskritik. Berlin, 1910.

2. Ver: ASMUTH, C. Salomon Maimon und die Transzendentalphilosophie ganz grundsätzlich. Em: Discipline Filosofiche 29. 2019. H. 1: Salomon Maimon: alle origini dell'idealismo tedesco, a cura di Luigi Azzariti-Fumaroli e Lidia Gasperoni, p. 31-46.

3. Ver: „Por isso, enquanto ciência ela tem que ser não apenas negligenciada, mas contestada positivamente e destruída.". ASMUTH, C. Fichtes Logik als Logikkritik. Em: Internationales Jahrbuch des deutschen Idealismus 12. 2014, p. 213-235.

4. Ver: ASMUTH, C. Wissen im Aufbruch. Die Philosophie der deutschen Klassik am Beginn der Moderne. Kultur - System - Geschichte; 14. Würzbur, 2018.

5. Sobre isso ver: ASMUTH, C. C. Von der Urteilstheorie zur Bewusstseinstheorie. Die Entgrenzung der Transzendentalphilosophie. Em: ders. (Hg.), Kant und Fichte - Fichte und Kant (Fichte-Studien; 32), Amsterdam vorauss, 2006.

6. Sobre a teoria de Fichte sobre a moral ver: C. de PASCALE. Die Vernunft ist praktisch. Fichtes Ethik und Rechtslehre im System. Berlin 2003; ASMUTH, C., METZ, W. (Hg.), Die Sittenlehre J. G. Fichtes. 1798-1812. Em: Fichte-Studien; 27, Amsterdam, 2006.

7. Ver: Die Anweisung zum seligen Leben (1806) - Asmuth, Christoph: Sein, Bewußtsein und Liebe. Johann Gottlieb Fichtes Anweisung zum seligen Leben. Publicado, explicado e com uma introdução feita por Christoph Asmuth. (excerpta classica) Mainz 2000.

8. Desconheço uma relação direta de Fichte a autores do neoplatonismo. Suspeito muito mais, que, através de Lutero, o pensamento agostiniano tem uma influência na teoria da imagem de Fichte. Ver: Yady Oren.

9. N.T.: O dicionário Duden indica que Metaebene pode ser uma superfície de partida assim como uma superfície superior.

10. Ver: ASMUTH, C.: Bilder über Bilder - Bilder ohne Bilder. Eine neue Theorie der Bildlichkeit. Darmstadt 2011.

11. Ver Christoph Asmuth: “'Eu procurava e cai cada vez mais fundo no labirinto.' Fichte e a fábula de Ariadne" Em: Revista de Estud(i)os sobre Fichte, 13, 2017, http://ref.revues.org/423

12. Sobre a filosofia prática ver além disso: ASMUTH, C., METZ, W. (Hg.), Die Sittenlehre J. G. Fichtes. 1798-1812. Em: Fichte-Studien; 27, Amsterdam/ New York, 2006. DE PASCALE, C.: Etica e diritto. La filosofia pratica de Fichte e le sue ascendenze kantiane. Bologna 1995; DE PASCALE, C.: Vivere in società, agire nella storia. Libertà, diritto, storia in Fichte. Milano 2001; DE PASCALE, C.: Die Vernunft ist praktisch`. Fichtes Ethik und Rechtslehre im System. Berlin, 2003; ZÖLLER, G. Fichte's Transcendental Philosophy. The Original Duplicity of Intelligence and Will. Cambridge, 1998.

13. Ver: BISOL, B. Körper, Freiheit und Wille: die transzendentalphilosophische Leiblehre J.G. Fichtes. Würzburg 2011; STACHE, A. Der Körper als Mitte: Zur Dynamisierung des Körperbegriffes unter praktischem Anspruch. Würzburg, 2009.

14. Ver: ZÖLLER, G, Setzen hält Leib und Seele zusammen. Fichtes transzendentale Somatologie und das System der Vernunft. Em: Kant und der Frühidealismus. System der Vernunft. Kant und der deutsche Idealismus, 2. STOLZENBERG, J. (Hg.). Hamburg, 2007, p. 129-151.

15. Ver: BÜCK, G. Herbarts Grundlegung der Pädagogik. Heidelberg, 1985.

16. Ver: WLADIKA, M. Moralische Weltordnung, Selbstvernichtung und Bildwerden, seeliges Leben - Johann Gottlieb Fichtes Religionsphilosophie. Würzburg, 2007.

17. Fichte a Carl Leonhard Reinhold em Kiel, 8 de janeiro de 1800, GA III, 4, S. 182.

18. Gen. 


\section{RESUMOS}

In this paper, the author discusses Fichte's concept of being and its redefinition within a theory of the image or, in other words: within a metaphysics that does not depart from being as principle. In this discussion, the author shows the effects of Fichte's transformation of ontology, which can be considered as an example of the changing in the conception of being after Kant, in the different domains of human life. The author argues that Fichte's theory of image does not explore the identity between being and God but the identity between the I or the Self and God and that, consequently, being obtains only a secondary role. Since, as the author affirms, Self and being are transmitted by the forming image [bildende Bild] and this transmission [Vermittlung] must be conceived in terms of self-transmission (Selbstvermittlung) that proves itself as self-determination. Rather than the authenticity of being, Fichte recognizes only the transmission of the finite self with itself-a process of actual formation with the aim of reconciling the human being with the world (s)he has created.

\section{ÍNDICE}

Keywords: God, Theory of Image, Ontology, self

\section{AUTOR \\ CHRISTOPH ASMUTH}

Berlín 